\title{
DOCUMENTO
}

\section{PORTARIA CIRCULAR № 2 DA DIRETORIA DE EDUCAÇÃO E SAÚDE PÚBLICA DO MUNICÍPIO DE PELOTAS (RS), 1941}

DOI: http://dx.doi.org/10.1590/2236-3459/73141

\author{
Patrícia Weiduschadt' \\ 'Universidade Federal de Pelotas (UFPel), Pelotas/RS, Brasil \\ Renata Brião de Castro" \\ "Universidade Federal de Pelotas (UFPel), Pelotas/RS, Brasil
}

\section{$\cos 80$}

PELOTAS, Diretoria de Educação e Saúde Pública, Portaria circular no 2 de 12 - 3 - 1941. Centro de Documentação e Obras Valiosas da Bibliotheca Pública Pelotense, Pelotas/RS.

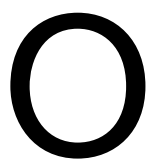

presente documento é uma portaria circular da Diretoria de Educação e Saúde Pública do município de Pelotas (RS) do ano de 1941. A mesma tem como objetivo regular e normatizar o trabalho dos professores e gestores das escolas do município. Assim, é descrito com grande número de detalhes vários itens para a organização escolar. No início do documento é solicitado que os responsáveis pelas escolas leiam com atenção as diretrizes presentes na portaria, dada a sua importância. A portaria, traz orientações, por exemplo, acerca da nacionalização do ensino. Nesta data (1941) a nacionalização era um assunto bastante recorrente, já estando em vigor a nacionalização compulsória do ensino, e o município de Pelotas contava (e conta) com um número significativo de imigrantes, por essa lógica era importante, na concepção da época e dentro desse contexto, que o poder público estivesse atento a essa questão e normatizasse a nacionalização do ensino, por meio da Diretoria de Educação e Saúde Pública. A Campanha de Nacionalização do Ensino foi bastante abrangente em todo 
o país. Contudo, a ação nacionalizadora foi mais nítida na região sul do Brasil, onde havia zonas de colonização. (SCHWARTZMAN, 1983, p. 362). Pode-se notar também, ao ler a portaria, que os aspectos da Escola Nova estão presentes nesse documento. No ano de 1932, é escrito o Manifesto dos Pioneiros da Escola Nova, o qual se apresentou como um instrumento, expressando a posição de um grupo de educadores, os quais viam, na troca. de governo em 1930, a oportunidade de exercer influência e controle na educação do país (SAVIANI, 2007). Os ideais presentes no manifesto estiveram presentes, pelo menos na teoria, nos documentos veiculados pelo poder público.

Outrossim, encontra-se no texto a valorização da psicologia e da biologia. São utilizados conceitos de pensadores da educação, o que denota que os responsáveis pela elaboração tinham certo conhecimento.

É importante pensar sobre a escrituração escolar, uma vez que a portaria indica como as escolas deveriam preencher os documentos. A exigência da escrituração escolar se acentua principalmente no governo de Getúlio Vargas, quando houve normatizações para o registro das atividades escolares. Estes documentos da escrituração escolar, nos fornecem indícios para compreender aspectos da história da instituição escolar. Para Gil e Hawat (2015) os livros de matrícula, mapas de frequência, atas de exames, diários de classes, livro ponto de professores, entre outros materiais são suportes da escrita escolar, os quais tem entre os propósitos fiscalizar e organizar as práticas escolares. Gil e Hawat (2015) trazem que pensar essa escrita é também refletir sobre a prática dos docentes que não se restringe somente a ensinar, mas ao que é registrado pelos professores e dão visibilidades a suas atividades e servem para apoiar a memória. Esses registros são suportes de memória de determinada instituição escolar e permitem conhecer os sujeitos da escola, nesse caso, os alunos.

Ainda, nota-se a portaria à alusão a comemoração de determinadas datas escolares, como por exemplo: dia do professor, dia da criança, dia da cultura nacional. Essa última relaciona-se com a nacionalização do ensino. Essas são alguns dos elementos presentes na portaria, a qual consideramos relevante para pensar o período em questão, bem como a organização do município de Pelotas (RS) no que diz respeito a escolarização pública.

\section{Referências}

GIL, Natália de Lacerda; HAWAT, Joseane EI. O tempo, a idade e a permanência na escola: um estudo a partir dos livros de matrícula (Rio Grande do Sul, 1895-1919).

Revista História da Educação, Porto Alegre, v. 19, n. 46, p. 19-40, 2015.

SAVIANI, Dermeval. História das ideias pedagógicas no Brasil. Campinas: Autores Associados, 2007.

SCHWARTZMAN, Simon; BOMENY, Helena Maria Bousquet; COSTA, Vanda Maria

Ribeiro. Tempos de Capanema. Rio de Janeiro: Paz e Terra, 1984.

\section{Referência do documento e localização}

PELOTAS, Diretoria de Educação e Saúde Pública, Portaria circular no 2 de 12 - 3 1941. Centro de Documentação e Obras Valiosas da Bibliotheca Pública Pelotense, Pelotas/RS. 
PORTARIA CIRCULAR № 2

\section{DIRETORIA DE EDUCAÇÃO E SAÚDE PÚBLICA}

\section{ÍNDICE}

Ano letivo - 1

Auxiliares de Ensino - 10

Assuntos suplementares -12

Boletins mensais - 5

Chefe Nacional - 4

Caixa Escolar -7

Dia da Criança - 3

Dia do professor - 3

Dia da Cultura Nacional - 3

Dia do Corpo de Deus - 4

Ensino objetivo - 8

Exposição de trabalhos manuais - 11

Ensino religioso e trabalhos escolares -11

Feriados Nacionais com obrigatoriedade da Bandeira - 4

Falta de alunos - 6

Faltas no magistério - 7

Férias - 7

Grandes datas não feriadas - 4

Horários - 1

Inspetoria técnica - 5

Iluminação das salas de aula - 10

Livro Ponto - 4

Livro de Chamada -6

Licenças -6

Matrícula - 1

Nacionalização do ensino - 8

Ordem das matérias - 10

Provas parciais e exames finais -2

Prêmios, homenagens, etc. -4

Privilégios -5

Prêmios escolares -7

Penalidades -7

Promoções por antiguidade e por merecimento - 8

Pesquisas por acuidade visual e auditiva do escolar - 11

Processologia dos trabalhos escritos escolares - 13

Recreio - 2 
Relatório semestral - 9

Relatório geral - 9

Trabalhos manuais -9

Transferências de professores -10

Resumo da processologia dos trabalhos escritos escolares

Comparecimento - 13

Dias letivos -13

Faltas -13

Frequência média - 13

Frequência durante o mês - 13

Frequência média mensal e anual (relatório geral) - 19

Matrícula líquida -13

Média das faltas -18

Movimento geral dos anos (boletim mensal) -18

Percentagem da frequência - 17

Percentagem das aprovações e das reprovações (relatório geral) - 19

Quadro "demonstrativo das provas parciais (relatório geral) - 19

Quadro demonstrativo A - (relatório geral) - 20

Quadro demonstrativo B - (relatório geral) - 21

\section{DIRETORIA DE EDUCAÇÃo E SAÚDE PÚBLICA}

Port ${ }^{\text {a }}$ Circ. № 2

Sr Prof.

Para a presente Portaria Circular requeiro a preciosa atenção de V S. Sua leitura atenta evitará dúvidas e possíveis interpretações errôneas, devendo V S manter sempre um constante contacto com esta diretoria, o que será de um salutar efeito para o ensino.

ANO LETIVO -

O ano letivo em todas as escolas compreende o período que vaí do primeiro dia útil do mês de março ao último dia útil do mês de novembro de cada ano.

HORÁRIOS -

O horário escolar passa a ser o seguinte: das 8 e $1 / 2$ às 11 e 45 , para os cursos de alfabetização (1ํano, método); das 13 e $1 / 2$ às 17 horas, para os alunos do $2^{\circ}, 3^{\circ}$, $4^{\circ}$ e $5^{\circ}$ ano; das 19 às 21 e $1 / 2$ horas, para as escolas noturnas.

O horário das escolas rurais é das 8 às 11 horas, passando a ser das 13 às 16 nos mêses de junho, julho e agosto, não havendo assim neste período aulas na parte da manhã.

Nos sábados uteis as aulas serão dadas na parte da manhã, mesmo nas escolas rurais durante os 3 meses acima referidos, não havendo aulas nesse dia na parte da tarde em qualquer escola.

Os Srs. Professores devem estar no recinto da escola 15 minutos antes dos 
horários mencionados acima, procurando manter a disciplina de seus alunos, organizandoos em fileiras para a entrada na sala de aula, a qual nunca deve ser retardada, afim de que o ensino não principie fóra do horário regular.

\section{DA MATRÍCULA}

O primeiro período da matrícula é o que vai de $1^{\circ}$ a 15 de março inclusive, iniciandose as aulas no primeiro dia útil imediato. O segundo período é o que vai de 16 a 30 de março para as escolas urbanas, e de 16 de março a 30 de abril para as escolas suburbanas e rurais, não podendo fóra destas épocas serem feitas matrículas novas, salvo as exceções previstas nesta portaria circular.

\section{fls. 2}

Recomendo a melhor atenção para que não sejam matriculadas crianças com menos de sete anos.

Quanto aos professores rurais que isoladamente dirigem a sua escola, não poderão ter matrícula superior a 40 alunos (quarenta) alunos em cada turno (no caso de haver mais de um turno).

Nas demais escolas a matrícula não poderá exceder de 35 (trinta e cinco) alunos por professor, em cada ano, isto para os alunos do $2^{\circ}, 3^{\circ}, 4^{\circ}$ e $5^{\circ}$ anos. Os professores de alfabetização não poderão ter a seu cargo mais de 30 (trinta) alunos.

Na matrícula devem ser inscrítos em primeiro lugar os alunos que passaram de ano e os alunos repetentes; só depois destes se farão as matrículas dos alunos NOVOS, na possibilidade das vagas existentes. As escolas noturnas terão no máximo 25 alunos por professor em casa ano.

Os alunos que já vinham frequentando as aulas só terão direito à matrícula em primeiro lugar até o dia 15 de março inclusive; aquêles que não a efetuarem dentro desse período ficarão em igualdade de condições com os alunos novos, sujeitando-se assim a não serem matriculados uma vez que não existam vagas.

Os alunos que estiverem sendo alfabetizados terão a seguinte divisão: de 7 anos a 10, em sala separada dos alunos de 11 a 14 anos, afim de que melhor se mantenha a disciplina e mais eficiente seja o ensino. Os alunos repetentes do curso de alfabetização devem ficar sózinhos numa sala, sem contacto com os alunos novos.

\section{RECREIO}

Durante o tempo de recreio, que será sempre de 20 minutos ao ar livre, tanto no turno da manhã como no turno da tarde, e uma vez em cada um dêles, os professores acompanharão a sua classe, observando os alunos, intervindo nos brinquedos, afim de orientá-los melhor e evitar o esgotamento físico semore prejudicial ao escolar. Os minutos de recreio serão aproveitados na metade do horário; nos dias de chuva êles se farão no recinto da escola. 


\section{PROVAS PARCIAIS E EXAMES FINAIS}

As provas parciais, em todas as escolas, se realizarão: a $1^{\text {a }}$ na primeira quinzena de junho e a $2^{\text {a }}$ na primeira quinzena de novembro.

O horário para cada disciplina não será superior a 50 minutos para o segundo, terceiro, quarto e quinto anos e nem a 60 minutos para o primeiro ano.

Os alunos que, por motivo justificado, não se apresentarem às provas parciais, nos períodos determinados, só poderão, fazê-las dentro dos primeiros 5 dias seguintes.

Em todas as provas observadas rigorósamente as

\section{fls. 3}

disciplinas do programa.

Os exames finais serão feitos pela média resultante das provas parciais e terão início no primeiro dia útil do mês de dezembro.

A média para cada disciplina não poderá ser inferior a 5 , não tendo, assim, promoção os alunos que não alcançarem a referida média.

Os professores, em cada prova parcial, deverão apresentar à Diretoria de Ensino a matéria dada e que será objeto da prova respectiva.

É terminantemente proibido o princípio da perguntas e respostas. Cada matéria de exame será objeto de uma tese sorteada para dissertação e de duas questões, valendo quatro pontos a tese e três pontos cada questão.

Nas escolas urbanas os alunos de alfabetização não estão sujeitos a provas parciais, mas prestarão exames orais e escrítos de português e aritmética na segunda quinzena de novembro, perante banca designada por esta diretoria. Nas escolas rurais e suburbanas esses exames se efetuarão na primeira quinzena de dezembro, juntamente com a apuração das médias finais.

Os alunos do quinto ano, quando não alcançarem média, serão submetidos a prova oral, sendo vago o exame da matéria, com a duração de 45 minutos no máximo. Este exame será feito imediatamente após a apuração da média nomeada por esta diretoria.

Os alunos transferidos de outras escolas, durante 0 ano letivo, serão sempre matriculados, embóra não haja vaga. Quando pertencerem a escolas sob esta direção serão matriculados, mediante guia de transferência, no mesmo ano em que estavam na outra escola, independente de exame de habilitação, exigindo-se este para alunos das demais escolas, dando-se ciência a esta diretoria em ambos os casos.

\section{5 de MARÇO}

"O Dia da Criança", que é o dia 25 de março, será sempre comemorado de acôrdo com o artigo 17 do Decréto Lei 2.024, de 17 de fevereiro de 1940.

\section{DIA DO PROFESSOR}

A 15 de outubro, "Dia do Professor", não haverá aula, sendo as homenagens prestadas de véspera. 


\section{DE NOVEMBRO}

O "Dia da Cultura Nacional", aniversário de Rui Barbosa, será comemorado na forma da circular 121, de 23 de outubro do ano passado.

\section{fls. 4}

\section{CHEFE NACIONAL}

A data de 19 de abril lembra o natalício do Presidente Vargas e merece comemoração especial.

\section{CORPO DE DEUS}

Não haverá aula nesse dia.

\section{PRÊMIOS, HOMENAGENS, ETC.}

Nenhuma escola poderá aceitar em caráter oficial prêmios, homenagens ou tomar parte em qualquer solenidade sem autorização desta diretoria.

\section{LIVRO PONTO}

O livro "ponto" de professores não poderá ser assinado pelos mesmos depois da hora regulamentar de entrada em aula e será rubricada pelo diretor ou pelos inspetores na própria escola, não precisando vir à diretoria.

\section{FERIADOS NACIONAIS COM OBRIGATORIEDADE DA BANDEIRA (Decreto Lei} 486 de 10 de junho de 1938)

$1^{\circ}$ de janeiro - Confraternização dos Povos

21 de abril - Tiradentes

1 을 de maio - Dia do trabalho

7 de setembro - Independência

2 de novembro - Finados

15 de novembro - Proclamação da República

25 de dezembro - Natal.

Todas as escolas comemorarão estas datas às 9 horas dos dias respectivos, fazendo os professores preleções aos alunos sobre o significado das mesmas, não havendo alas nesses dias. As escolas noturnas farão as comemorações nas vésperas, antes de encerrar os trabalhos.

Nas festas cívicas, que são os grandes dias santos da Pátria, é obrigatório o comparecimento de todos os professores e alunos, sob pena de lhes ser contada falta nesse dia, (artigo 224, XV, do decreto Lei 1. 713, de 28 de outubro de 1938). Excetuam-se, aqui, os que estiverem legalmente licenciados ou dispensados. 


\section{GRANDES DATAS NÃO FERIADAS}

14 de abril - Dia "Pan-Americano" (hasteamento da Bandeira)

3 de maio - Descobrimento do Brasil.

13 de maio - Abolição da Escravatura.

24 de maio - Batalha do Tuiutí.

11 de junho - Batalha do Riachuelo.

14 de julho - Tomada da Bastilha.

fls. 5

12 de outubro - Descobrimento da América.

10 de novembro - Promulgação da Constituição Brasileira de 1937.

19 de novembro - Dia da Bandeira.

A data de 10 de novembro de 1937 será sempre comemorada com a compra da fundação do Estado Nacional, devendo o professor fazer preleção sobre o significado da mesma.

Além do que ficou expresso, comemorações especiais - serão prestadas na "Centenária, cujo período de férias é de 27 de junho a 7 de julho inclusive; no dia 21 de setembro, que é o dia da "arvore", e a 19 de novembro, dia da "Bandeira".

$\mathrm{Na}$ Semana Santa as comemorações serão prestadas na forma da circular ํㅡㄴ 2, de 4 de abril de 1939.

Em qualquer parada cívico-social só poderão tomar parte crianças maiores de 10 anos, ficando aos cuidados dos professores indagarem se as mesmas alimentaram-se convenientemente; a criança que não tenha tomado alimento algum não poderá formar na mesma, evitando-se assim, desfalecimentos que viriam perturbar o brilho da concentração.

\section{PRIVILÉGIOS}

Dentro do quadro do magistério não existe, em qualquer de suas categorias, nenhum privilégio. Os professores, que são funcionários públicos, estão sujeitos a servir em qualquer escola para que foram designados. Ficam excluídos, aqui, os professores rurais que não tenham concurso urbano, não podendo, assim, passar de um quadro para outro.

\section{INSPETORIA TÉCNICA}

À Inspetoria Técnica estão subordinados todos os professores, diretores e regentes. Das decisões da mesma cabe recurso para o diretor e deste para o Prefeito.

Os Inspetores exercerão ampla e rigorosa fiscalização na administração do ensino, orientando os professores e ministrando aulas "modelo", quando isto se fizer necessário, e estarão em contacto direto e permanente com o diretor, informando-o das faltas e irregularidades encontradas, bem como da competência dos professores.

Até o dia 10 de janeiro os inspetores ficam obrigados a entregar ao diretor relatório 
minucioso dos serviços, com todos os dados indispensáveis para a estatística educacional.

Os "boletins mensais" serão conferidos e rubricados pelos inspetores, atestandoos como certos e verídicos.

\section{BOLETINS MENSAIS}

fls. 6

A inobservância na escrituração exata dos boletins mensais não dará direito a que o professor ou professores recebem seus vencimentos, até que o mesmo boletim esteja corretamente preenchido.

Os boletins das escolas noturnas urbanas devem ser entregues à Inspetoria Técnica no dia $1^{\circ}$ de cada mês; os das escolas diurnas urbanas e suburbanas no máximo até 0 dia 2 às 10 horas; os das escolas rurais até o dia 3.

A não entrega dos boletins nesta diretoria, em duas vias, até os dias acima referidos dará margem a que a falta seja punida de acôrdo com o Decreto Lei oํ 1.413 , de 28 de outubro de 1938, e na forma do que já ficou recomendado.

Os professores rurais, no dia 3 de cada mês, deverão entender-se diretamente com a Inspetoria Técnica para obter esclarecimentos referentes ao ensino.

\section{LIVRO DE CHAMADA}

Todas as escolas ao trazerem os boletins mensais devem apresentar nessa ocasião os livros de chamada dos alunos, afim de serem conferidos e visados pelos inspetores. Esses livros já devem trazer o visto das diretoras ou regentes.

Em hipótese alguma o livro de chamada poderá estar fora do recinto da escola nos períodos em que esta estiver em plena atividade. A não observância deste preceito dará margem a que o professor seja punido, perdendo um dia de seus vencimentos, isto quanto à primeira inobservância; nas reincidências a penalidade será da perda de cinco dias dos vencimentos.

\section{FALTA DE ALUNOS}

Os alunos que, sem motivo justificado, perante a direção técnica do ensino letivo tiverem mais de 30 faltas consecutivas ou 60 intercaladas durante o ano letivo, não poderão fazer exames.

\section{LICENCCAS}

Todo e qualquer funcionário para ausentar-se do município precisa anteriormente licença expressa do Prefeito e a forma regulamentar é o requerimento.

Quando se trata de licença para o tratamento da saúde e estando o funcionário impossibilitado de locomover-se deverá mencionar no requerimento essa particularidade, indicando, então, a rua onde reside e o número do prédio afim de facilitar a inspeção.

As licenças até 15 dias, e nunca em prorrogação, podem ser dirigidas, por ofício, 
ao diretor.

\section{fls. 7}

As licenças serão sempre contadas na data do afastamento do funcionário e não da data de requerimento ou ofício.

$\mathrm{Na}$ forma do artigo 156 da Constituição, letra $\mathrm{H}$, parte final, as professoras gestantes têm direito a 90 dias de licença, com vencimentos integrais.

\section{FALTAS NO MAGISTÉRIO}

A fim de que seja regularizado o desconto em folha de pagamento no caso de faltas, estas deverão ser enviadas a esta diretoria até as 16 horas do dia 25 de cada mês. As faltas que desta data de seguirem até o último dia do mês serão computadas nas faltas do mês seguinte e assim sucessivamente.

Pelas irregularidades nos descontos, sem culpa desta diretoria, ficarão responsáveis as diretoras, regentes e professores de escolas isoladas.

\section{CAIXA ESCOLAR}

De acôrdo com o artigo 130, da constituição de 10 de novembro de 1937, devem os professores exigir dos alunos mais favorecidos, no mínimo 200 réis por mês como contribuição da Caixa Escolar.

\section{PRÊMIOS ESCOLARES}

Quando qualquer pessoa jurídica ou física conferir prêmios, de qualquer natureza, a alunos ou professores, deve a escola beneficiada por sua direção dar imediato conhecimento a esta diretoria da natureza do prêmio, do instituidor e do beneficiado.

\section{FÉRIAS}

Os professores só tem direito às férias regulamentares de 30 dias; as férias escolares são exclusivamente para os alunos. Assim, os professores estão sujeitos a ser chamados para qualquer serviço educacional, quando a isto obrigarem os altos interêsses do ensino. professores.

À Inspetoria Técnica cabem os mesmos princípios que regulam as férias dos

\section{PENALIDADES}

As faltas dos diretores, regentes e professores, serão punidas pela forma seguinte:

a) advertência pelos Inspetores,

b) repressão pelo Diretor,

c) suspensão pelo Diretor, até 15 dias sem vencimentos.

Em qualquer reincidência será aplicada em dobro a penalidade da letra $\underline{c}$. 
fls. 8

Aos alunos serão aplicados as penalidades de advertência por escrito aos pais e suspensão até 5 dias, imposta pelos inspetores. A penalidade de exclusão é privativa do diretor.

Os inspetores, ao aplicarem a penalidade de suspensão, estão obrigados a dar por escrito conhecimento ao diretor.

Os castigos físicos são terminantemente proibidos, bem como os castigos de ordem moral que possam diminuir ou ridicularizar o aluno perante os seus companheiros, como seja o fato, por exemplo, de colocar, durante a hora de aula, a criança de pé a um canto da sala. Castigos dessa natureza implicarão na exclusão do Quadro do Magistério.

Nenhum aluno será privado do recreio regulamentar e nem ficará preso em aula depois do horário de saída para cumprir qualquer penalidade. Quando houver estas, o aluno as fará em sua casa.

\section{PROMOÇÕES POR ANTIGUIDADE E POR MERECIMENTO}

Quanto as datas de nomeação ou promoção coincidirem entre vários professores, a escolha se fará pelo número do ato, decreto ou portaria mais antigo, e quando estes forem iguais entre si e iguais forem as datas de nomeação ou promoção, a escolha recairá no funcionário mais velho.

As promoções por merecimento obedecerão ao seguinte critério: será escolhido o professor que tiver o menor número de faltas na frequência e o melhor aproveitamento da promoção de classe, preponderando, sempre, o aproveitamento de classe.

Merecerá também igual promoção o professor que, a critério da diretoria, tiver prestado serviços relevantes ao ensino.

\section{NACIONALIZACCÃO DO ENSINO}

Qualquer professor, quando tiver conhecimento de que uma escola não está observando as leis de nacionalização do ensino, é obrigado a trazer o fato ao conhecimento desta diretoria, afim de são se cumpliciar com os transgressores da Lei.

\section{ENSINO OBJETIVO}

Nenhum professor poderá, sob qualquer pretexto, afastar-se do método ANALÍTICO-OBJETIVO-DEDUTIVO.

Nota: os Srs. Professores poderão apresentar a esta diretoria, até dezembro do corrente ano, sugestões parciais ou totais sobre o programa do ensino, a fim de serem devidamente estudados, pois o objetivo deste departamento é facilitar o mais possível a aplicação do programa em benefício do próprio aluno. 
fls. 9

\section{RELATÓRIO SEMESTRAL}

Dentro do período que vai de27 de junho a 7 de julho os diretores e regentes de Grupos Escolares, os professores de escolas isoladas bem como os de escolas noturnas, devem apresentar a esta diretoria o relatório circunstanciado dos trabalhos escolares com dados estatísticos da matrícula geral e da matrícula real. A isto estão obrigados, também, os professores de dactilografia e os de trabalhos manuais. Entretanto não fôr entregue o relatório, os responsáveis pelo mesmo não receberam seus vencimentos.

\section{RELATÓRIO GERAL}

O relatório mimeografado, que todos os professores devem receber em setembro, tem que ser devolvido a esta diretoria (devidamente preenchido e assinado) por qualquer dos membros da comissão de exames, imediatamente à conclusão do mesmo exame. Ao não cumprimento do que está expresso deverá ser aplicado o artigo 243 de Decreto Lei 1.713, de 28 de outubro de 1938.

\section{TRABALHOS MANUAIS}

O horário de serviço das professoras de trabalhos manuais será o seguinte:

Corte e costura - 3 horas diárias na parte da manhã para os Grupos Escolares "Joaquim Assunção" e "Dona Antonia", sendo que o professor atenderá três vezes na semana para-cada grupo, deixando seus auxiliares atenderam nos outros dias e 2 horas de trabalho diário, três vezes por semana todos os dias, sempre na parte da manhã, para as outras escolas.

Bordado, trabalhos de serra, de cartolina, modelagem, etc. -3 horas diárias de trabalho, sendo três vezes na parte da manhã e 3 vezes na parte da tarde. (1 horas e 1/2 na parte da manhã e 1 hora e $1 / 2$ na parte da tarde) para o "Joaquim Assumpção" e para 0 "Dona Antônia", sendo três vezes na semana para casa grupo e horas de trabalho diário 1 hora na parte da manhã e 1 hora na parte da tarde) 3 vezes na parte da manhã e 3 vezes na parte da tarde para as escolas. Cada ano ou classe não receberá menos de duas lições por semana, com a duração mínima de 35 minutos e máxima de 45 .

As senhoras professoras não se afastarão das aulas durante o tempo de trabalho, dando assistência afetiva aos alunos e cordial aos demais professores.

Davam obediência direta às diretoras e às regentes das escolas onde lecionarem e assinarão o ponto na escola em que estiverem empregando a sua atividade.

É vedado às professoras de trabalhos manuais imporem às crianças a qualidade da fazenda ou do material que as mesmas devem trazer para a confecção do que lhes fôr determinado.

Esta diretoria solicita às professoras de classe colaborarem com as de trabalhos manuais, auxiliando-as sempre que fôr fls. 10 possível, sem prejuízo dos interêsses de seus alunos. 


\section{AUXILIARES DE ENSINO}

É dever das auxiliares de ensino fazer a correção das provas escritas, manter a disciplina de classe, auxiliar a professora de classe no que fôr preciso, ficando a direção e a responsabilidade do ensino afeta inteiramente à professora.

\section{TRANSFERÊNCIA DE PROFESSORES}

Até o dia 15 de abril os senhores professores deverão fazer seus pedidos de transferência, afim de serem eles estudados e atendidos na medida do possível; fora dessa época, essas transferências far-se-ão apenas quando houver nisso interesse do ensino.

\section{ILUMINAÇÃO DAS SALAS DE AULA}

Deve esta ser unilateral, feita pela esquerda. A iluminação bilateral perturba a visão, não deixando aos olhos o necessário repouso. Por conseguinte, em salas que tenham janelas dos dois lados, não se fará uso daqueles que ficarem à direita do aluno.

\section{ORDEM DAS MATÉRIAS}

Para as que pedem mais alto esforço da mente, atenção mais firme e concentrado, devem ser reservadas (no turno da manhã) as primeiras horas de aula, quando a mente do aluno, perfeitamente repousada, se encontra mais apta a raciocinar, assimilando melhor a explicação do mestre. Ficarão as horas seguintes para as disciplinas que exigem mais a comparticipação dos sentidos do que o trabalho intenso do cérebro.

No turno da tarde, atendendo-se ao fenômeno digestivo que se segue ao almosso, para que trabalho mental e trabalho fisiológico não se prejudiquem mutuamente, deve o professor deixar para as últimas horas de aula matérias que exijam menos esforço e energia mental, maior permeabilidade do cérebro, como geografia e matemática, por exemplo. Não deve haver fixação prévia de conhecimentos (Decroly) sem ter em conta os interêrres da criança (princípio de liberdade de Rousseau).

\section{MEMÓRIA}

Como bem afirmou Montaigne: "Saber de cór não é saber"

É preciso que o professor simplifique as suas lições, que as torne completamente claras e simples, bem objetivadas, sem dissertações abstratas estéreis, afim de que o aluno as compreenda sem sombras de vacilação ou dúvida.

\section{fls. 11}

É necessário que a memória seja um instrumento inteligente, disciplinado, e para isto ela precisa da cooperação de juízo e do raciocínio.

Faça-se a criança raciocinar, julgar, para compreender e realizar.

De que serve guardar sem compreender?

Precisamos aulas ativas, de ensino experimental, manual.

Vendo e executando, o aluno aprenderá melhor do que enchendo a sua cabecinha 
com as regras teóricas.

\section{EXPOSIÇÃO DE TRABALHOS MANUAIS}

Ficam terminadas as exposições de trabalhos manuais no fim do ano letivo com caráter oficial.

Serão esses trabalhos expostos por ocasião da primeira e da segunda provas parciais e no dia da apuração das médias (exame final).

Como visam eles o aprendizado da criança e não a demonstração de coisas belas que não sejam simplesmente esforço do escolar, é preciso que se mostre apenas o trabalho da proposta criança, a fim de que se averigue o gráu do seu aproveitamento.

\section{ENSINO RELIGIOSO E TRABALHOS ESCOLARES}

Os senhores professores devem observar rigorosamente o quadro demonstrativo das disciplinas e a circular ํㅜ 70, de 18 de maio de 1938, sendo que esta fica alterada da forma seguinte: "o ensino religioso será ministrado com duração máxima de 20 minutos".

Quando o professor estiver lecionando uma disciplina e não a tenha dado por concluída, não poderá interromper a mesma para que seja ministrada outra matéria.

Apesar do horário ser livre, nenhum professor poderá ministrar aulas com duração superior a 45 minutos.

\section{PESQUIZAS DA ACUIDADE VISUAL E AUDITIVA DO ESCOLAR}

Como é de utilidade imperiosa a estreita cooperação do professor e do médico na execução das necessárias pesquisas em torno da saúde da criança, e como o serviço da higiêne escolar também se estende ao professor, que deve ser um elemento inteligente de colaboração com o médico, determino que, no começo de cada ano letivo, por ocasião da matrícula, seja pesquisada a acuidade visual e auditiva de cada aluno da seguinte maneira, fácil de ser executada, aconselhada por Aristides Ricardo, no seu livro "Biologia aplicada a educação:"

\section{fls. 12}

Acuidade visual - O professor desenhará uma figurinha bem preta (a de um gato, por exemplo) do tamanho de um centímetro quadrado no máximo, sobre um cartão branco, de 12 por 15 centímetros, pregado numa parede clara, que não receba luz direta. $A$ distância de 10 metros da figura, far-se-à no chão um risco a giz. De $1 / 2$ em $1 / 2$ metro. Novos riscos serão feitos até as proximidades do desenho. Cada aluno em separado, sem que se comuniquem entre si, será colocado sobre o risco mais afastado. É assim virá, sempre sozinho, rumo ao cartão pregado à parede, olhando-o de cada um dos traços feitos no chão.

Quando reconhecer a figura, terá aferida a sua acuidade visual.

O professor poderá assim organizar melhor a sua classe, sentando nas carteiras da frente os alunos que tenham menor capacidade de visão. 
Acuidade auditiva - sobre o vértice craneano da criança o professor segurará um relógio de bolso. Se a audição fôr normal, o tic-tac será perfeitamente ouvido.

Os alunos que menos ouçam também serão colocados nas primeiras carteiras.

Verificadas anormalidades nesses dois principais sentidos, serão então as crianças portadoras desses defeitos físicos encaminhados de imediato ao "Centro de Saúde ํㅜ 5, onde receberão os cuidados do médico especialista.

Lembro aos senhores professores exercitarem todos os órgãos sensoriais dos pequenos escolares valendo-se dos jogos chamados "jogos dos sentidos".

\section{ASSUNTOS SUPLEMENTARES}

As serventes estão obrigadas a lavagem e limpeza geral das escolas onde servirem todos os sábados na parte da tarde, independente da limpeza diária das mesmas. No período de férias a escola deve ser aberta, arejada e completamente limpa duas vezes por semana, ou na parte da manhã ou na parte da tarde.

Nenhuma escola poderá fornecer dados, de qualquer natureza, sobre o ensino, sem autorização desta diretoria.

As escolas noturnas devem matricular alunos de qualquer idade, não atendendo as limite máximo de 14 anos. Êsse limite, nas escolas diurnas, é só para efeito da matrícula inicial.

\section{fls. 13}

PROCESSOLOGIA DOS TRABALHOS ESCRITOS ESCOLARES

(Livro de chamada de alunos, boletim mensal, relatório anual.)

Matrícula líquida (real ou atual" = comparecimento + faltas

Dias letivos

Exemplo: 600 comparecimentos

$$
+\frac{200 \text { faltas }}{800+20 \text { dias letivos }}=40 \text { (matrícula líquida) }
$$

Comparecimentos: = matrícula líquida $\mathrm{X}$ dias - faltas

Exemplo: 40 (matrícula líquida)

20 (dias)

800

$$
\frac{-200 \mathrm{f} .}{600 \mathrm{c} .}
$$

Faltas: $=$ matrícula líquida $\mathrm{X}$ dias - comparecimentos

Exemplo: 40 (mat. Líq.)

20 (dias) 
800

$\frac{-600 \mathrm{c} .}{200 \mathrm{f} .}$

Dias letivos: Comparecimento + faltas

Matrícula líquida

Exemplo: $600 \mathrm{c}$.

$$
\frac{+200 \mathrm{f} .}{800 / 40} \text { (mat. Líq.) }=20 \text { dias letivos }
$$

Frequência média $=$ matrícula líquida $X$ dias letivos - faltas

$$
\text { Dias letivos }
$$

ou melhor

$$
\frac{\text { Comparecimentos }}{\text { Dias letivos }}
$$

Exemplo: 40 (mat. Líq.)

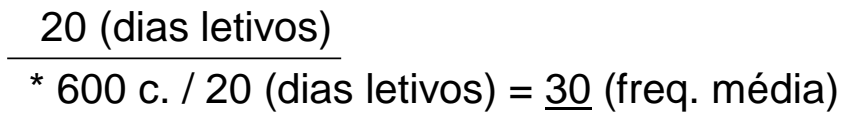

ou

600 c. $/ 20$ (dias letivos) $=\underline{30}$ (freq. média)

Faltaram, em média, 10 alunos
A frequência média foi de 30 alunos
$30+10=40$ alunos
(Matrícula líquida)

fls. 14

$\mathrm{Na}$ frequência média, quanto o resto da divisão é maior que a metade do divisor, aumenta-se 1 no resultado.

Exemplo: 593 c. 24 (dias letivos)

11324 (25) frequência média

17 (mais que $\underline{12}$, que é metade de $\underline{24}$ ). 
A frequência média é então 25 e não 24.

Faz-se o trabalho por sexo e por ano apenas. O mais é simples soma para achar o total por sexo e o total geral (boletim mensal).

Modo de achar a frequência média quando é dividendo é menor que o dividor:

Exemplo: 22 comparecimentos $=1$ (freq. média)

24 dias letivos

\begin{tabular}{lc}
22,0 & 24 \\
\hline 04 & $/ 0,9(1)$
\end{tabular}

22 comparecimentos $=0$

24 dias letivos

\begin{tabular}{cc}
9,0 & 24 \\
\hline 18 & $/ 0,3(0)$
\end{tabular}

Como é preferível não trabalhar com fração, se esta fôr alta $(0,6-0,7-0,8-0,9)$ se escreverá 1 , e se fôr baixa $(0,2-0,3-0,4)$ não se escreverá nada ou se escreverá 0 .

Quando alguns alunos (no começo do ano letivo, enquanto está aberta a matrícula) começam a frequéntar as aulas em qualquer dia que não seja o primeiro dia em qua as aulas principiarem a trabalhar, contam-se os comparecimentos dos outros alunos todos (ou que frequentarem, as aulas desde o primeiro dia) e divide-se a soma desses comparecimentos todos pelo número de dias letivos para achar-se a frequência média mensal desses alunos. Depois então, em separado, tiram-se as médias dos primeiros. Podemos fazer por meio de frações ordinárias. O número de comparecimentos e faltas do aluno será o denominador (soma de cc e ff) e o número de comparecimentos será o numerador (soma só de cc menos os ff). Reduzem-se essas frações todas, de denominadores diferentes, ao mesmo denominador, somam-se e extraem-se os inteiros (aumentando-se 1 a estes, se o resto fôr maior que a metade do divisor). Se um aluno só teve comparecimentos e não teve faltas, é 1 a ser acrescentado, porque sabemos que uma fração de numerador igual ao denominador fls. 15 é equivalente a uma unidade a um inteiro.

Exemplo: C C C C $=\frac{4=1}{4}$

\section{Demonstração:}

Figuremos os nomes dos alunos pelas seguintes letras:

$A-B-C-D-E-F-G$

A - (começou a frequentar o colégio no $1^{\circ}$ dia do mês).

$\mathrm{B}$ - (começou a frequentar o colégio no dia 18).

C- (começou a frequentar o colégio no dia 15).

D - (começou a frequentar o colégio no dia 19).

$\mathrm{E}$ - (começou a frequentar o colégio no $1^{\circ}$ dia do mês).

$\mathrm{F}$ - (começou a frequentar o colégio no dia 17). 
G - (começou a frequentar o colégio no dia 12.).

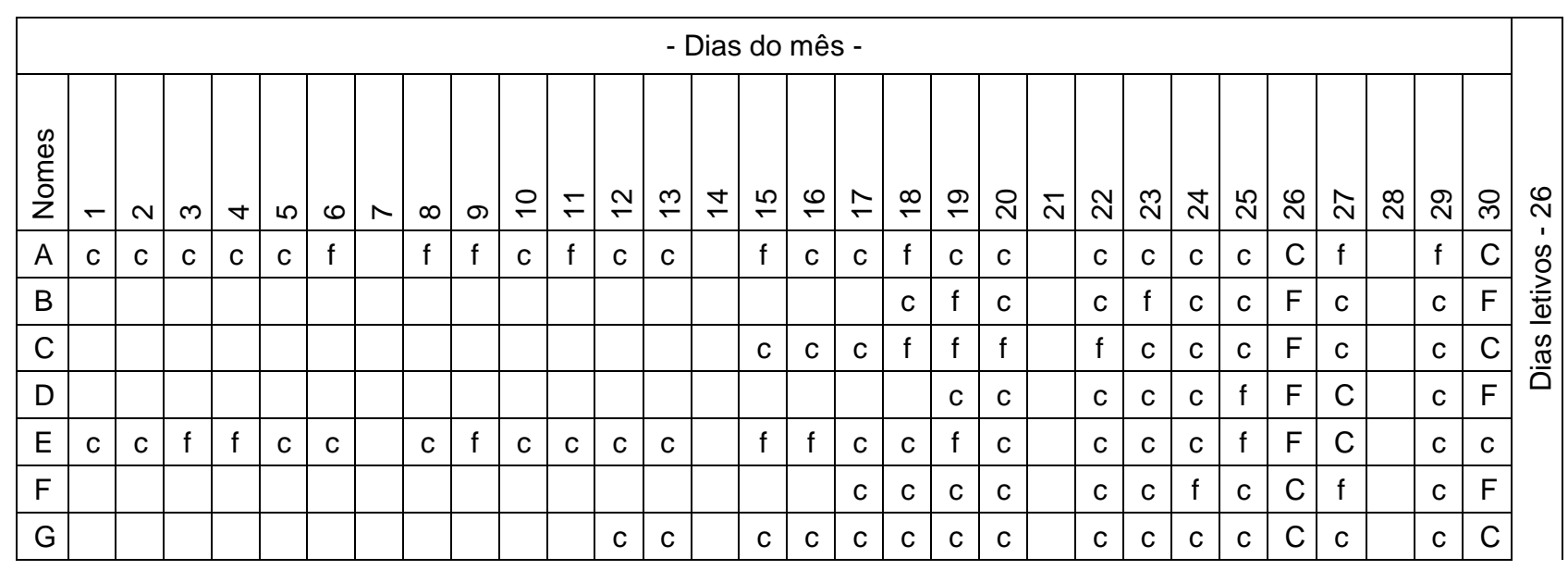

Tira-se a frequência média dos alunos $\underline{A}$ e E dividindo-se a soma de seus comparecimentos pelos dias letivos (26). Portanto:

35 c. 26 (dias letivos

09 / $\underline{1}$ (freq. média de $\underline{A}$ e $\underline{E}$

A frequência média do aluno $\underline{G}$ é $\underline{1}$, porque só teve comparecimentos: $16=1$

Vejamos a frequência média dos outros alunos:

(B) $7 \quad(7=\mathrm{c}$.

$1111=\mathrm{C}=\mathrm{f})$

(C) $8 \quad(8=\mathrm{C}$.

$1414=\mathrm{C}=\mathrm{f})$

(D) $7 \quad$ (7 $=$ C.

$1010=\mathrm{C}=\mathrm{f})$

(F) $9 \quad(9=\mathrm{C}$.

$1212=\mathrm{C}=\mathrm{f})$

(G) $16 \mathrm{C}=1$ (frequência média de G)

fls. 16

$7+8+7+9=2940+2640+3234+3465+3465=12279=$

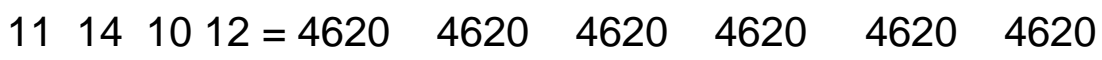

420) 330) 462) 385) = 3 (freq. média de B, C, D, F.)

1227 / 4620

30392 (B) (Aumenta-se 1, porque o resto 3039 é maior que a metade do divisor 4620).

Portanto, a frequência média é 5 . 
Vejamos:

1 (Freq. média de $A$ e $E$ )

+1 (Freq. média de $\mathrm{G}$ )

3 (Freq. média de B, C, D, F)

5 (Freq. média de todos)

O denominador comum das frações é achado procurando-se o menor múltiplo comum dos denominadores.

Exemplo:

(Processo algébrico)

$$
\begin{array}{l|l}
11-14-10-12 & 2 \\
11-7-5-6 & 2 \\
11-7-5-3 & 3 \\
11-7-5-1 & 5 \\
11-1-1-1- & 11 \\
1-1-1-1 &
\end{array}
$$

$2^{2} \times 3 \times 5 \times 7 \times 11=4620$

(Processo aritmético)
(Por esse processo tomam-se todos os expoentes. É o processo mais fácil)

$$
\begin{aligned}
& 11=11 \\
& 14=2 \times 7 \\
& 10=2 \times 5 \\
& 12=2^{2} \times 3
\end{aligned}
$$$$
2^{2} \times 3 \times 5 \times 7 \times 11=4620
$$

(Por este processo tomam-se apenas os maiores expoentes).

O aluno excluído ou eliminado (cancelado na matrícula) desaparece, no boletim mensal, da matrícula líquida, pois vai figurar sob o título "Eliminados". Seu nome continua no "livro de matrícula e no livro de "chamada dos alunos". Na coluna "Eliminados" do "Livro de Chamada" e do "boletim mensal" só aparece o número dos alunos eliminados dentro daquele mês, apenas naquele mês. Quero dizer que se não repete esse número nos meses consecutivos. Esses alunos eliminados desaparecem dos 2 quadros sob os títulos seguintes: "Nacionalidade dos alunos" e "Idade dos alunos" (boletim mensal). Estes 2 quadros, pois, têm que ser iguais a matrícula líquida (boletim mensal).

\section{fls. 17}

No quadro sob o título: "Frequência durante o mês" (livro de chamada dos alunos) se encontrarmos, por exemplo, 35, 34, 32, 31, colocaremos o ponto bem em cima da linha que corresponde a 30 . Se, ao contrário, encontrarmos mais de $35(36,37,38,39)$ colocaremos o ponto que marca a percentagem da frequência diária bem em cima da linha 
que corresponde a 40. E assim em todos os casos, isto quer dizer que os pontos (ligados) pelas linhas quebradas) são colocados sempre sobre as linhas horizontais do quadro e não fora delas.

Percentagem da frequência $=$ comparecimento $X 100$

Matrícula líq. $X$ dias letivos

$\mathrm{Ou}$

Frequência média $\times 100$ (melhor)

Matrícula líquida

Exemplo:

$600 \mathrm{c}$.

$\mathrm{x} 100$

$(40 \times 20)$

60000

$8 \emptyset \emptyset$ (mat. Líq. X dias)

48

$75 \%$ (perc. Da freq.)

$\mathrm{Ou}$

X 30 (freq. média)

100

$4 \emptyset$ (mat. Líq.) (melhor)

$300 \emptyset$

75\% (perc. Da freq.)

20

0

Se não houvesse faltas nos 20 dias, a percentagem da frequência dos 40 alunos seria $100 \%$. A metade, ou 20 alunos, se não faltassem, teriam a percentagem de frequência $50 \%$. Houve faltas (200).

Logo: 40 alunos $-100 \%$

$$
\begin{aligned}
& 20 \text { alunos }-50 \% \\
& 30 \text { alunos }-75 \%
\end{aligned}
$$

Frequência durante o mês:

Frequência do dia $\times 100$

Matrícula líquida

Exemplo:

18 meninas

+22 meninos 
40 alunos (frequência do dia)

$40 \times 100$

40 (mat. Líq.) $=100 \%$

fls. 18

Médias das faltas $=$ mat. Líq $X$ dias let. - comparecimentos

Dias letivos

Exemplo:

40 (mat. Líq.)

$\frac{\mathrm{X} 20 \text { (dias) }}{800}$

$-600 \mathrm{c}$.

$200 \mathrm{~F} .2 \emptyset$

10 (média das faltas)

Frequência média $=30$ alunos

Média das faltas $=10$ alunos +

Mat. Líquida $=40$

No boletim mensal, na parte sob o título "Movimento Geral" dos anos", onde está escrito "frequência", o professor porá a frequência média; onde está escrito "Matrícula", será escriturada a matrícula líquida e não a matrícula geral,

No boletim mensal, na parte sob o título "Resumo", o trabalho será assim feito no cômeço do ano letivo: na coluna "Matrícula Geral" o professor escreverá o número de alunos que estão matriculados; na coluna "Matrícula líquida", nomeará os que já estão frequentando as aulas; na parte sob o título "observações" porá o número daquêles que, apesar de matriculados, ainda não começaram a frequentar as aulas.

Exemplo:

\begin{tabular}{|c|c|c|c|c|}
\hline \multirow{2}{*}{ Anos } & \multicolumn{2}{|c|}{ Matrícula Geral } & \multicolumn{2}{c|}{ Matrícula líquida } \\
\cline { 2 - 5 } & Masculin. & Femin. & Masculin. & Femin. \\
\hline $1^{\circ}$ & 14 & 16 & 12 & 16 \\
\hline $2^{\circ}$ & 20 & 15 & 20 & 11 \\
\hline $3^{\circ}$ & 17 & 18 & 16 & 15 \\
\hline
\end{tabular}


Etc.

Na coluna "observações" o professor esclarecerá:

No $1^{\circ}$ ano masculino 2 alunos ainda não começaram a frequentar

\section{fls. 19}

as aulas.

No $2^{\circ}$ ano feminino 4 alunas ainda não principiaram as aulas.

No $3^{\circ}$ ano masculino 1 aluno, e no $3^{\circ}$ feminino 3 alunas ainda não estão frequentando as aulas.

No relatório geral (página "Frequência média mensal e anual"). $O$ trabalho será assim feito: achar-se-á a frequência média mensal fazendo-se a divisão dos comparecimentos mensais pelo número de dias úteis do mês, e achar-se-á a frequência pela anual dividindo-se o número de comparecimentos anuais pelos dias letivos anuais. Quando a fração fôr de 5 décimos ou mais, acrescentar-se-á uma unidade.

A percentagem das aprovações e das reprovações (relatório geral) é achada multiplicando-se o número de alunos aprovados e reprovados por 100 e dividindo-se pela matrícula líquida. $O$ mesmo trabalho também se fará sobre a matrícula geral em nova página que para esse fim será acrescentada ao relatório.

Os totais dos quadros com o título "Demonstrativo das provas parciais" (relatório geral) têm que ser iguais aos totais dos quadros sob o título: - "Aproveitamento dos alunos", somando-se os alunos aprovados com os reprovados em cada uma das provas parciais. A média por sexo é obtida somando-se a percentagem das provas e dividindo-se pelo número delas.

As médias totais parciais são obtidas somando-se as médias por sexo e dividindose por 2 (sexos masculino e feminino). As médias totais gerais são obtidas somando-se as medias todas e dividindo-se pelo número de classes ou anos. Vão os exemplos nos quadros demonstrativos A e B.

Somando-se a percentagem dos alunos aprovados com a percentagem dos alunos reprovados tem que dar sempre $100 \%$ (isto para o $2^{\circ}, 3^{\circ}, 4^{\circ}$ e o $5^{\circ}$ ano).

Para o $1^{\circ}$ ano, em separado, será acrescido o relatório de uma nova página.

Neste ano somar-se-á a percentagem dos alunos aprovados (alfabetizados) com a dos alunos reprovados e com a daquêles que, estando alfabetizados, por motivo justificado não fizerem exame final.

Fazendo-se a soma desses três quadros, tem que aparecer sempre $100 \%$.

fls. 20

No comêço do ano letivo seguinte, esses alunos alfabetizados que não fizeram exame final, por motivo justificado, sujeitar-se-ão a um exame pela professora de $2^{\circ}$ ano, afim de vêr se estão habilitados a frequentar esse ano. 
Exemplo:

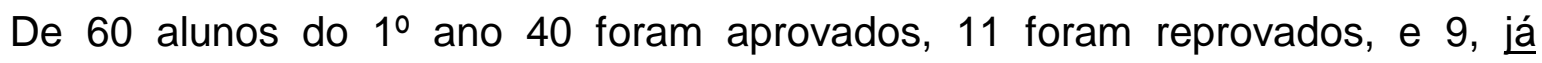
alfabetizados, não compareceram ao exame por motivo justificado.

Então:

$67 \%$ é a percentagem dos aprovados, $18 \%$ é a percentagem dos reprovados, $15 \%$ é a percentagem dos alfabetizados que não puderem comparecer ao exame final.

$67 \%+18 \%+15 \%=100 \%$

Pelotas, 20 de fevereiro de 1941.

Assinatura do diretor

fls. 21

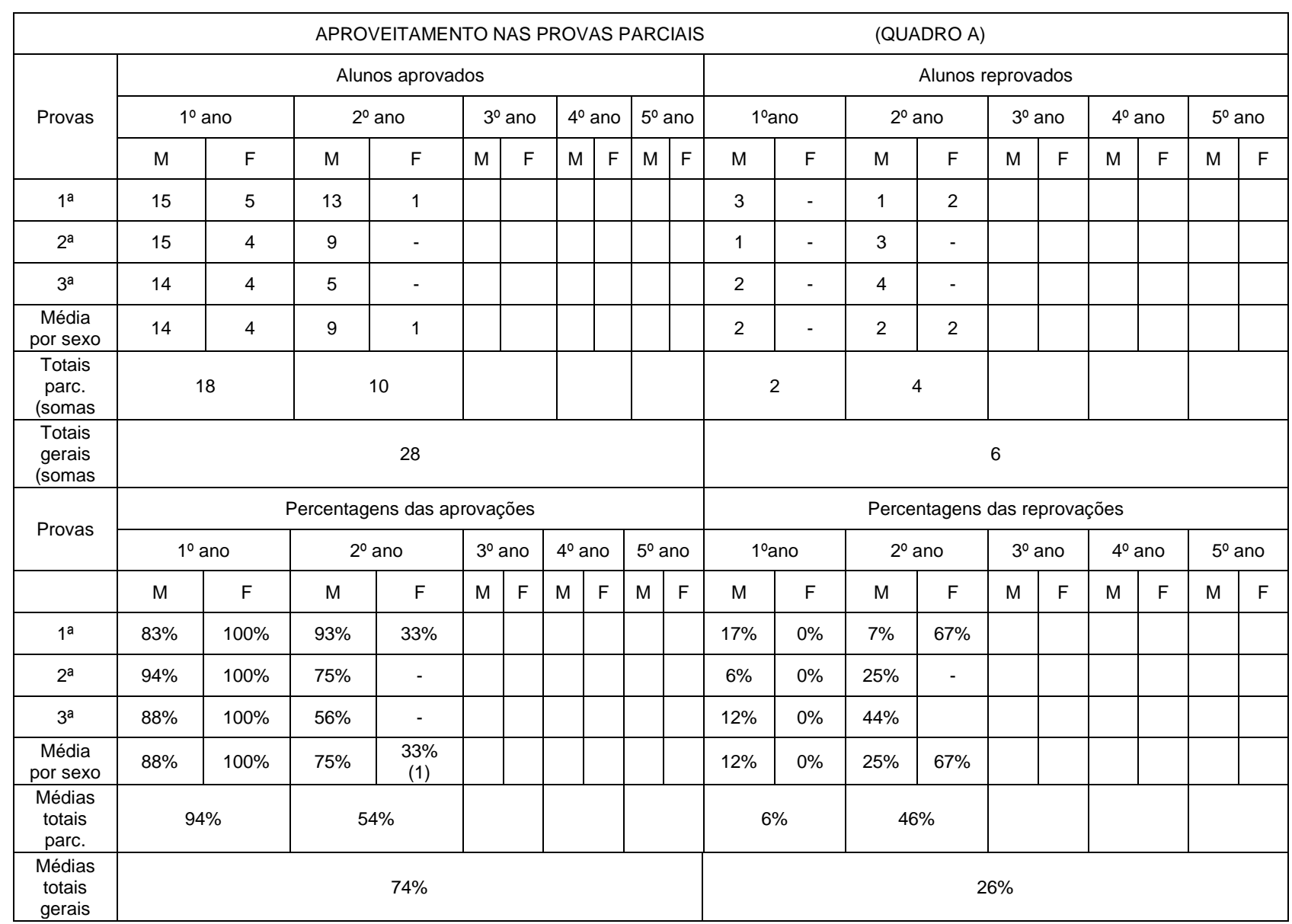

(Sobre a matrícula líquida, acrescenta-se uma unidade quando a fração fôr de 5 décimos ou mais)

(1) $\left(33 \%\right.$ é a média por sexo do $2^{\circ}$ ano feminino, porque as alunas só fizeram a $1^{\underline{a}}$ prova e foram eliminadas).

Não se poderia, portanto, dividir por 3, número de provas. 
PATRÍCIA WEIDUSCHADT é professora na Faculdade de Educação e no Programa de PósGraduação em Educação na Universidade Federal de Pelotas (UFPel), Doutora em Educação pela Universidade do Vale do Rio dos Sinos (Unisinos).

Endereço: Rua Laura Lang, 321, Bairro Três Vendas, 96020-630, Pelotas/RS, Brasil.

E-mail: prweidus@gmail.com

RENATA BRIÃO DE CASTRO é doutoranda no Programa de Pós-Graduação em Educação na Universidade Federal de Pelotas (UFPel).

Endereço: Rua Dr. João Pessoa, 354 A, Bairro Centro, 96010-470, Pelotas/RS, Brasil.

E-mail: renatab.castro@gmail.com

Recebido em 04 de maio de 2017.

Aceito em 28 de maio de 2017. 